\title{
analytycicalistryCaltech Library
}

Subscriber access provided by Caltech Library

\section{Article}

\section{Glucose Sensing Using Surface-Enhanced Raman-Mode Constraining}

Daejong Yang, Sajjad Afroosheh, Jeong Oen Lee, Hyunjun Cho, Shailabh Kumar, Radwanul H. Siddique, Vinayak Narasimhan, Youngzoon Yoon, Alexey T. Zayak, and Hyuck Choo

Anal. Chem., Just Accepted Manuscript • DOI: 10.1021/acs.analchem.8b03420 • Publication Date (Web): 29 Oct 2018

Downloaded from http://pubs.acs.org on October 29, 2018

\section{Just Accepted}

"Just Accepted" manuscripts have been peer-reviewed and accepted for publication. They are posted online prior to technical editing, formatting for publication and author proofing. The American Chemical Society provides "Just Accepted" as a service to the research community to expedite the dissemination of scientific material as soon as possible after acceptance. "Just Accepted" manuscripts appear in full in PDF format accompanied by an HTML abstract. "Just Accepted" manuscripts have been fully peer reviewed, but should not be considered the official version of record. They are citable by the Digital Object Identifier (DOI®). "Just Accepted" is an optional service offered to authors. Therefore, the "Just Accepted" Web site may not include all articles that will be published in the journal. After a manuscript is technically edited and formatted, it will be removed from the "Just Accepted" Web site and published as an ASAP article. Note that technical editing may introduce minor changes to the manuscript text and/or graphics which could affect content, and all legal disclaimers and ethical guidelines that apply to the journal pertain. ACS cannot be held responsible for errors or consequences arising from the use of information contained in these "Just Accepted" manuscripts. 
Diabetes is a global chronic disease with no cure, ${ }^{1}$ requiring frequent monitoring and active management of glucose levels to prevent complications and improve patient outcomes. ${ }^{2,3}$ Presently, the glucose level in a body is commonly measured using disposable enzymatic sensors that meter changes in current generated by glucose oxidation in a small sample of blood. ${ }^{4,5}$ However, in addition to short shelf-lives due to the intrinsic instability of enzymes and dependence on environmental conditions, the major drawback has been the painful and inconvenient extraction of blood required for testing..$^{6-9}$ Less painful approaches using microneedles for blood extraction or measuring glucose in sweat or the interstitial fluid of skin provide less accurate measurements due to the small sample size or the significantly lower glucose levels in interstitial fluid and sweat compared with blood. ${ }^{10-15}$ Nonenzymatic electrochemical approaches have also been explored to overcome the instability of enzymes, however these approaches lack specificity for glucose, ${ }^{16}$ and the sensing electrodes develop surface fouling caused by glucose oxidation. ${ }^{16-18}$

Alternatively, optical approaches have been investigated for implementing minimally or non-invasive intensity-based glucose sensing, ${ }^{19-26}$ but their use in practical applications has been severely limited by their insufficient sensitivity and low repeatability ${ }^{19,20}$ (See Supporting Information). Raman spectroscopy is no exception because glucose naturally exhibits weak Raman signals due to its small Raman scattering crosssection, measuring only $5.6 \times 10^{-30} \mathrm{~cm}^{2} / \mathrm{molecules} /$ steradians or about 14 orders of magnitude smaller than fluorescence, and glucose Raman emission is easily overshadowed by strong background noises from the surrounding environment. ${ }^{25-27}$ To increase the Raman emission, researchers have employed nanostructure-based surface-enhanced Raman scattering (SERS), which amplifies weak Raman signals by a factor of $10^{6}$ - $10^{8} .28-32$ Because glucose molecules do not possess chemical affinity for SERS-substrate materials such as gold or silver, researchers used decanethiol (DT), mercaptohexanol (MH), and bisboronic acid as SERS-linker molecules and reported glucose detection down to $1 \mathrm{mM} \cdot{ }^{33-37}$ However, large linker molecules keep the glucose molecules away from the nearfield enhancement of the substrate surface and make it difficult to achieve more sensitive and consistent measurements. ${ }^{38-40}$ Glucose concentration has also been estimated by detecting an increase in Raman emission of the linker molecule mercaptophenylboronic acid (MPBA) or comparing relative intensity changes between two adjacent peaks of MPBA when glucose molecules are attached to MPBA. ${ }^{40,41}$ The former approach showed little increase in Raman emission while the latter approach was valid only in a highly acidic environment with a $\mathrm{pH}$ level close to $1.40,41$ 
Here, we demonstrate quantitative, continuous, and rapid sensing of glucose at physiologically observed levels by tracking the shifts in the MPBA's surface-enhanced Ramanemission peaks. The peak shifts directly result from the bonding of glucose molecules onto the hydroxyl group of MPBA (Figure 1a, b), and we designed the SERS substrates to provide a broad enhancement over the wavelength range of interest (Figure 2).$^{40}$ We also identified the underlying mechanism of the Ramanpeak shift caused by glucose bonding onto MPBA using numerical simulations (Figure 3) and experimental measurements. Bonding of glucose significantly influences elasticity of a MPBA molecule, which changes the molecular geometries and Raman-scattering cross sections of two " $\mathrm{C}$ ring" vibrational modes (Figure 3 ). When a glucose molecule bonds, the MPBA's C-ring mode at $1071 \mathrm{~cm}^{-1}$ (Figure 3e) becomes suppressed while the weakly active $\mathrm{C}$-ring mode at $1098 \mathrm{~cm}^{-1}$ (Figure 3f) changes its vibrational geometry to highly active "constrained-bending" and shifts its peak location to $1084 \mathrm{~cm}^{-1}$ (Figure 1b). As a result, the position of the hybridized peak between 1071 and $1084 \mathrm{~cm}^{-1}$ shifts as a function of the glucose concentration, and using this approach, we measured glucose from 0.1 to $30 \mathrm{mM}$ and demonstrated in ex vivo rabbiteye measurements an accuracy within $\pm 0.5 \mathrm{mM}$ of readings obtained using a commercial glucose sensor.

To our knowledge, Raman-peak shifting has previously been utilized for several sensing applications, ${ }^{42-46}$ yet tracking a Raman-peak shift that results from Raman-mode constraining has not been used for glucose sensing. And, tracking the SERSpeak shift proves to be a more reliable and consistent method to measure glucose concentrations than intensity-based SERSsensing approaches. ${ }^{44}$ SERS-emission intensity is directly influenced by the enhancement factors of SERS substrates that typically show large spatial and chip-to-chip fluctuations, whereas the positions of the Raman-emission peaks are determined by the vibrational states of the molecules and highly independent of the enhancing performance of individual substrates. ${ }^{46}$ Moreover, boronic acid is a biocompatible molecule, ${ }^{47-49}$ and its covalent bonding with glucose is rapid and also reversible, ${ }^{50,51}$ making our approach potentially promising for in vivo continuous sensing applications.

\section{RESULTS AND DISCUSSION}

For SERS-substrate fabrication, we selected a fabrication process previously developed for strong Raman enhancement and excellent spatial uniformity; ${ }^{52,53}$ and further engineered the process to produce substrates optimized for this glucosesensing application, providing excellent broadband SERS response over the relevant spectral range from $785 \mathrm{~nm}$ (the excitation-laser wavelength) to $858 \mathrm{~nm}$ (or $1084 \mathrm{~cm}^{-1}$, the target glucose-Raman emission). ${ }^{28}$ The fabrication was performed in a two-step process: (1) hydrothermal synthesis of $\mathrm{ZnO}$ nanowires (NWs) (Figure 2a); and (2) liquid phase deposition of Au nanoparticles (NPs) on the ZnO NWs (Figure 2b). ${ }^{52}$ The $\mathrm{ZnO} N W$ s produced in the first step serve as skeletal frames for Au-NP deposition, determine the periodicity, width, and height of the final Au-NP pillars, and gradually dissolve away during the second process step, leaving hollow vertical perforations that serve as light passages (Figure 2c, 2d, and S1c). To find an optimal geometry of the SERS substrates, we varied the concentration of zinc nitrate hexahydrate in the presence of the nanowire-growth-limiting hexamethylenetetramine (HMTA) in the precursor solution during the first process step, synthesized
$\mathrm{ZnO}$ nanowires of 4 different diameters, 50, 90, 180, and 230 $\mathrm{nm}$ (Figure S1a), and performed the near infrared absorption spectroscopy and finite element simulations (Figure 2e-g). The results show that the substrates with $50-\mathrm{nm} \mathrm{ZnO}$ NWs provide almost constant broad absorption $(>85 \%)$ over the relevant spectral range between 785 and $858 \mathrm{~nm}$, which can be also confirmed by the pitch-black appearance of the processed wafer (Figure S1d). ${ }^{28,52}$ The fabricated substrate also exhibited a high Raman enhancement factor around $9.31 \times 10^{9}$ and excellent uniformity indicated by the low relative standard deviation (RSD) below $4 \%$ over $1 \times 1-\mathrm{mm}^{2}$ area (See Supporting Information and Figure S1e, f). ${ }^{52}$

Using the fabricated substrates, we measured SERS spectra of $1 \mathrm{mM}$ MPBA in pure phosphate buffered saline (PBS) solution and PBS containing $10 \mathrm{mM}$ glucose (Figure S2a). In both cases, two major peaks were observed between 1070-1075 $\mathrm{cm}^{-1}$ and $1570-1580 \mathrm{~cm}^{-1}$. The former is the "breathing" mode assigned to $\mathrm{C}-\mathrm{S}$ stretching coupled with $\mathrm{C}$-ring expansion, and the latter is a mode assigned to B-C stretching coupled with $\mathrm{C}$ $\mathrm{C}$ stretching in-ring. ${ }^{41,54}$ For the double peak structure between $1570-1580 \mathrm{~cm}^{-1}$, the low and high frequency peaks correspond to MPBA with three and two hydroxyl groups, respectively (Figures S2b, c). MPBA naturally has two hydroxyl groups. When MPBA is exposed to mildly basic (alkaline) conditions (e.g., $\mathrm{pH}$ 7.4 PBS solution), the molecule acquires an additional hydroxyl group to form $\left(\mathrm{OH}^{-}\right)$-MPBA ion, which has been reported to have a higher affinity for bonding with glucose. ${ }^{41,55}$ Our numerical simulations showed the two forms of MPBA behave similarly with regard to the glucose-detection mechanism reported in this work, and we considered the three hydroxyl groups structure for the following discussions. When the MPBA-assembled substrate was immersed in the $10 \mathrm{mM}$ glucose solution, the measured peak at $1071.5 \mathrm{~cm}^{-1}$ shifted to $1072 \mathrm{~cm}^{-1}$ (Figure S2d) due to the changes in the dominant peak intensities.

The peak-shifting mechanism can be explained by performing a series of numerical simulations of the SERS spectra of MPBA with and without bonding glucose (Figure 3). MPBA or $\left(\mathrm{OH}^{-}\right)-\mathrm{MPBA}$ attaches to the Au substrate using a thiol group (Figure 3a), and glucose bonds on the hydroxyl group of MPBA through a dehydration reaction (Figure $3 b$ ). Two of the three hydroxyl groups of $\left(\mathrm{OH}^{-}\right)$-MPBA bond with glucose, and the third is left unoccupied. Figures $3 \mathrm{c}$, d show SERS spectra of $\left(\mathrm{OH}^{-}\right)-\mathrm{MPBA}$ and glucose-bound $\left(\mathrm{OH}^{-}\right)$MPBA obtained using density functional theory (DFT) simulations. For both MPBA and $\left(\mathrm{OH}^{-}\right)-\mathrm{MPBA}$ without glucose, two large peaks were observed at $1071 \mathrm{~cm}^{-1}$ and 1098 $\mathrm{cm}^{-1}$. The peak at $1071 \mathrm{~cm}^{-1}$ is dominant in this scenario, and originates from the coupled $\mathrm{C}-\mathrm{S}$ stretching and the $\mathrm{C}$-ring breathing motions shown in Figure 3e. The peak at $1098 \mathrm{~cm}^{-1}$ is assigned to the $\mathrm{C}-\mathrm{S}$ stretching coupled with the C-ring bending motion (shown schematically in Figure $3 \mathrm{f}$ ). In the case of glucose-bonded $\left(\mathrm{OH}^{-}\right)$-MPBA, the peak assigned to the $\mathrm{C}$-ring "breathing" mode becomes negligible, while the C-ring "bending" mode peak becomes dominant and redshifts to 1084 $\mathrm{cm}^{-1}$, due to the constraint imposed by glucose (Figure $3 \mathrm{~g}$ ). Overall, the bonding of glucose shifts the dominant Raman peak from $1071 \mathrm{~cm}^{-1}$ toward $1084 \mathrm{~cm}^{-1}$. The molecular structures in Figure $3 \mathrm{e}-\mathrm{g}$ and Supplementary Video 1 show the three motions discussed: (1) C-S stretching-coupled C-ring "breathing" mode of $\left(\mathrm{OH}^{-}\right)$-MPBA, (2) C-S-stretching-coupled C-ring "bending" mode of $\left(\mathrm{OH}^{-}\right)-\mathrm{MPBA}$, and (3) C-S-stretching-coupled C-ring 
"constrained-bending" mode of $\left(\mathrm{OH}^{-}\right)-\mathrm{MPBA}$ bound with glucose.

The theoretical results matched experimental results, however the magnitudes of the peak shift in the simulations are larger than in the experimental data due to the inherent approximations of the DFT method. In the experimental measurement environment, unoccupied MPBA molecules are expected to co-exist with glucose-bound $\left(\mathrm{OH}^{-}\right)-\mathrm{MPBA}$ molecules in the laser-probing spot, and the location of the peak will be an average between the unoccupied MPBA molecules and glucose-bound $\left(\mathrm{OH}^{-}\right)$-MPBA molecules peaks. If the ratio of glucose-bound $\left(\mathrm{OH}^{-}\right)$-MPBA to unoccupied MPBA increases, the peak will shift closer to the theoretical value of $1084 \mathrm{~cm}^{-1}$.

Glucose bonding can also affect the B-C-stretching-coupled $\mathrm{C}-\mathrm{C}$ stretching mode of MPBA near $1580 \mathrm{~cm}^{-1}$ in a highly acidic environment with $\mathrm{pH}$ close to $1 .{ }^{40} \mathrm{We}$ have verified, however, that this change does not occur in our mildly basic environment using $7.4 \mathrm{pH}$ PBS solution (Figure S2e). In addition, we also verified that it is difficult to directly observe the SERS peaks of glucose molecules. As shown in Figures S2f, g, no peaks were observed at the expected locations indicated by the blue arrows up to $10 \mathrm{mM}$ glucose. ${ }^{35}$ Collectively these results supported tracking the $1071 \mathrm{~cm}^{-1}$ MPBA's SERS peak to provide a more accurate and reliable method to detect glucose concentrations.

In order to experimentally correlate peak-shift behavior to glucose concentration, SERS spectra of MPBA were measured in the presence of $0.1-30 \mathrm{mM}$ glucose in PBS. This measurement range covers low glucose concentrations found in the aqueous humor of healthy adults as well as high concentrations observed in diabetic blood samples. ${ }^{56-58}$ The measurements were performed inside the polydimethylsiloxane (PDMS) chamber as shown in Figure S3. The plots in Figures $4 \mathrm{a}$ and $4 \mathrm{~b}$ show the positions of the hybridized SERS peak as a function of glucose concentration varying from 0.1 to $30 \mathrm{mM}$ in PBS. As discussed earlier, this hybridized peak results from MPBA's C-S-stretching-coupled C-ring "breathing" and "bending" modes that are significantly influenced by glucose bonding, and are easily observed due to their large combined emission intensity. Figure 4a shows SERS spectra of MPBA in the presence of glucose concentrations ranging from 0 to 30 $\mathrm{mM}$. The spectra were normalized with respect to the highest peak around $1071.5 \mathrm{~cm}^{-1}$. The initial peak position of MPBA in PBS was $1071.5 \mathrm{~cm}^{-1}$, and it shifted toward larger wave numbers as the glucose concentration was increased (Figure 4b). Figure 4c shows the peak position of MPBA logarithmically increased with increasing glucose concentrations.

Figure $4 \mathrm{~d}$ shows the initial dynamic response of our peakshifting approach when measured in PBS with $0.1,1$, and 10 $\mathrm{mM}$ glucose. We applied additional Savitzky-Golay filter in the time domain (See Method and Supporting Information, Figure S5). Upon injecting the glucose solution into the measurement chamber, the hybridized peak began to shift to the right, and its position approached the saturation point over a period. For higher glucose concentrations, the peak shifting and saturation occurred more rapidly when the concentration reached $10 \mathrm{mM}$.

The reaction between MPBA and glucose and the relationship between the peak wavenumbers follow the first order reaction rate equation: 49

$$
W_{n}=W_{0}+A \cdot(\exp (-t / \tau)-1) \quad \text { Eq. } 1
$$

where $W_{n}, W_{0}, A, t$, and $\tau$ represent the peak wavenumber in glucose solution, the peak wavenumber in PBS solution, real constant, time, and time constant, respectively; as the glucose concentration increases, the rate of peak shift increases. We formulated an analytical glucose-sensing model to predict the device response at various concentrations ranging from 0 - 30 $\mathrm{mM}$ (see Supporting Information and Figure S5 for more details).

The standard way to estimate the glucose concentration using Raman-mode constraining is to measure the peak shift directly after the reaction has reached an equilibrium and the peak position has almost finalized. The measurement speed of this method requires approximately 10 to 30 minutes depending on the glucose concentration (Figure S5 (a-c)). Predicting the concentration from the initial slope of the peak shifting is accurate and fast, which can be completed within 1 minute. For systems that start from a standard baseline or where the initial glucose concentration $\left(\mathrm{C}_{\text {initial }}\right)$ is known, the slope method can be as accurate as the peak position shift, as shown in Figure S5. A stand-alone slope method has not been tested for dynamically changing environments because it requires pre-knowledge of $\mathrm{C}_{\text {initial }}$ to improve the estimation of $\mathrm{C}_{\text {final }}$. Extensive comparisons between the final peak-shift and initial slope methods as well as a combination of these two methods in dynamically changing environments will be pursued in the future, building upon the work presented in this manuscript.

Next, we tested our approach for its reversibility and ability to track ambient glucose concentrations, important factors for continuous monitoring. The weak association constant of phenylboronic acid with glucose $\left(4.6 \mathrm{M}^{-1} \text { at } \mathrm{pH} 7.4\right)^{59}$ is advantageous for real-time continuous sensing of concentrations of glucose. Glucose molecules maintain a dynamic equilibrium between association and disassociation with MPBA, allowing continuously changing glucose concentrations in solution to be monitored. We performed dynamic response testing by placing a MPBA-coated chip in the PDMS test chamber and alternating the ambient solution between PBS and $10 \mathrm{mM}$ glucose PBS solutions. When the glucose solution was injected into the chamber the peak shifted to a larger wavenumber, and when the glucose line was turned off and the PBS solution line was turned on, the peak returned to the initial location. Due to the relatively weak bonding force between MPBA and glucose, our approach showed reversible peak shifting and continuous monitoring of the glucose concentration as shown in Figure S5g. ${ }^{49-51,59}$

Achieving reliable and stable measurements over an extended period is an important criterion for practical application of sensors, especially implantable devices. Hence, we tested the long-term usability of our approach by measuring the SERS-peak locations in a $10 \mathrm{mM}$ glucose PBS solution for one month. As shown in Figure S6, the device produced a very stable sensing result during the test period. The average daily drift of the peak position over this period was $-0.0006 \mathrm{~cm}^{-1}$ per day, which is highly encouraging for long-term continuous glucose monitoring.

Fructose, which has five hydroxyl groups, can also bond with MPBA in a similar manner and shift MPBA's Raman peak. ${ }^{60,61}$ However, the concentrations of fructose observed in aqueous humor, urine, and blood are typically one-thousandth to onehundredth of the glucose concentrations, ${ }^{56,62,63}$ and thus, its influence on our glucose measurement is considered negligible. 
As a feasibility study, we measured glucose concentrations in the aqueous humor of fresh ex vivo rabbit eyes using the Ramanmode constraining approach. Eyes are light-friendly biological structures suitable for optical sensing. In addition, we use polydimethylsiloxane (PDMS) to fabricate the implant mount for our SERS disks. PDMS is a biocompatible material, ${ }^{64,65}$ and has been utilized for the fabrication of implantable medical devices as well as ocular implants in the past. ${ }^{66-68}$ In the ciliary body, the aqueous humor is produced by diffusion and ultrafiltration of blood plasma through the ciliary body. ${ }^{69}$ As a result, the glucose concentration in the aqueous humor follows the blood glucose level more consistently and closely than other bodily fluids such as tears. ${ }^{56-58,69,70}$ The glucose range of 0.1-30 $\mathrm{mM}$ in the aqueous humor corresponds to $0.1-60 \mathrm{mM}$ in blood, which covers the physiologically relevant glucose levels observed in normal and diabetic conditions.

The anterior chamber of human eyes has emerged as an optimal site for compact, minimally-invasive medical implants, providing easy optical accessibility for convenient and remote monitoring of various aspects of human health. ${ }^{71}$ For the ex vivo measurements, we fabricated C-shaped PDMS implants mounted with SERS disks (Figure 5a-c and Experimental Procedures in Supporting Information). The C-shaped PDMS, measuring $1 \mathrm{~mm}$ in arm width, is elastic and flexible, it can be folded in half as shown in Figure 5d. This allowed for insertion through a small incision in the cornea, and, when released, the folded implant self-restored back to its original $\mathrm{C}$ shape and positions itself inside the anterior chamber as shown in Figure 5e (Experimental Procedures in Supporting Information and Figure S7). We performed the ex vivo eye measurements as shown in Figure 5f. The SERS implants were positioned about halfway between the center and the edge of the cornea (Figure $5 \mathrm{e}$ ), and the optical transmittance of a fresh rabbit cornea is over $90 \%$ between 520 and $870 \mathrm{~nm}^{72}$ The laser light passes through the cornea and reaches the SERS disk placed off the optical axis of the eye, mainly exposing the cornea to the laser light. Risk of thermally damaging the cornea is minimal because the cornea has high transmittance (over $95 \%$ at $785 \mathrm{~nm}$ ), and the tissues show minimum absorption at $785 \mathrm{~nm} .{ }^{72}$ We measured the glucose concentrations of the rabbit aqueous humor using the SERS implants and compared the values with concurrently obtained readouts from a commercially available electrochemical glucose sensor with an accuracy of $\pm 15 \%$ in $99 \%$ of the measurements for glucose concentration above 4 $\mathrm{mM}$ (Figure $5 \mathrm{~g}$ ). All of the data measured by the implanted sensor were located in the region A of the Clarke error grid (Figure 5h). Our SERS sensors produced robust Raman peaks with high intensity and positions that were easily tracked. Our Raman-mode-constraining approach produced measurements that matched the readouts concurrently obtained from the commercial sensor within $0.5 \mathrm{mM}$. This error range is acceptable for use with diabetic patients ${ }^{73}$ whose glucose concentrations would typically vary on the order of $10 \mathrm{mM}$.

\section{CONCLUSION}

We have investigated Raman-mode constraining of MPBA resulting from glucose bonding, identified its underlying mechanism in simulation studies, and demonstrated quantitative, accurate glucose sensing in an on-chip microfluidic environment as well as in ex vivo rabbit eyes. Glucose-MPBA bonding modifies two of MPBA's Raman modes, resulting in a peak shift whose magnitude can be correlated to the ambient glucose concentration.

Our approach overcomes naturally weak SERS signals of glucose, shows good resistance against enhancement variations that are inherent to SERS substrates, and it could potentially allow monitoring continuously changing glucose concentrations at levels observed in the aqueous humor and blood. Future studies will focus on developing implantable devices with improved Raman enhancement, signal-to-noise ratios, and concentration-readout speed to pursue measurements in living animals and ultimately in humans. With further improvements, these results may open up a path for practical SERS-based in vivo glucose sensors. 
a

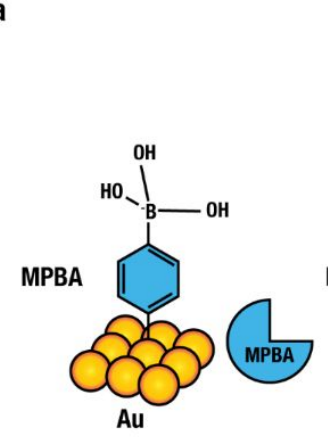

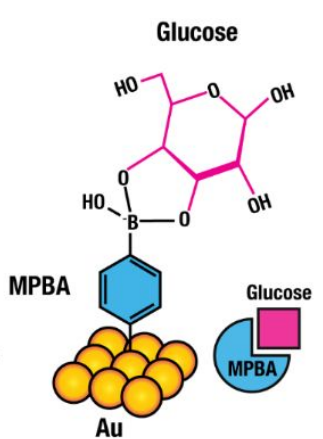

b

5

6

7

8

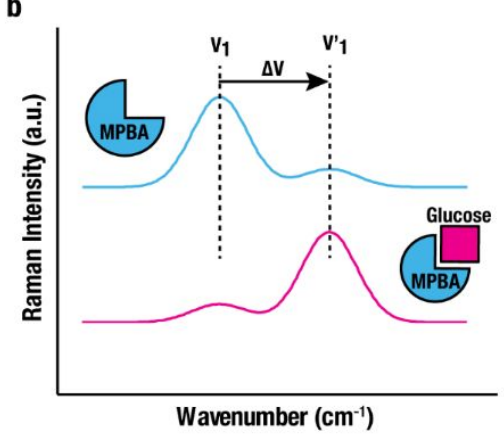

C

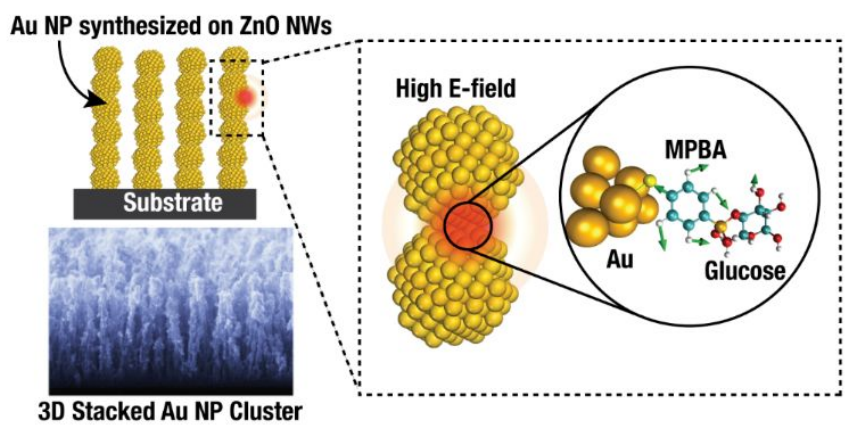

Figure 1. Glucose-detection mechanism based on SERS-peak shifting. (a) Schematic illustrations of MPBA (left) and glucose-bound MPBA (right). (b) A shift in the dominant Raman peak of MPBA from $v_{1}$ to $v_{1}$ ' resulting from glucose bonding with MPBA. (c) Schematic illustration and SEM of highly uniform surface-enhanced Raman scattering using 3D Au-NP clusters stacked in a vertical pillar arrangement.
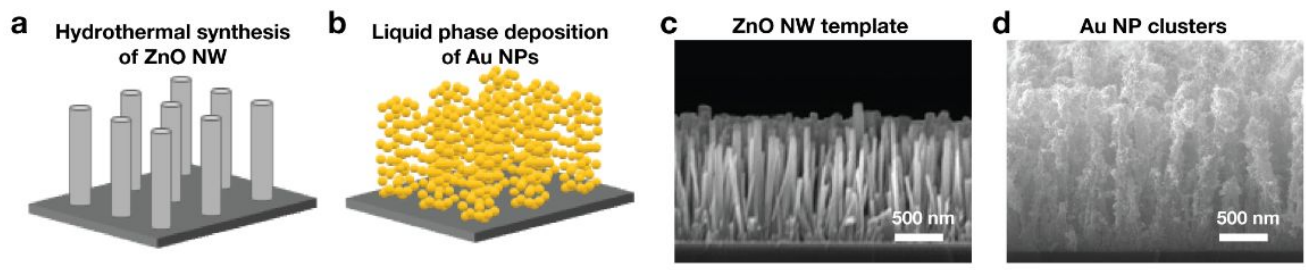

e
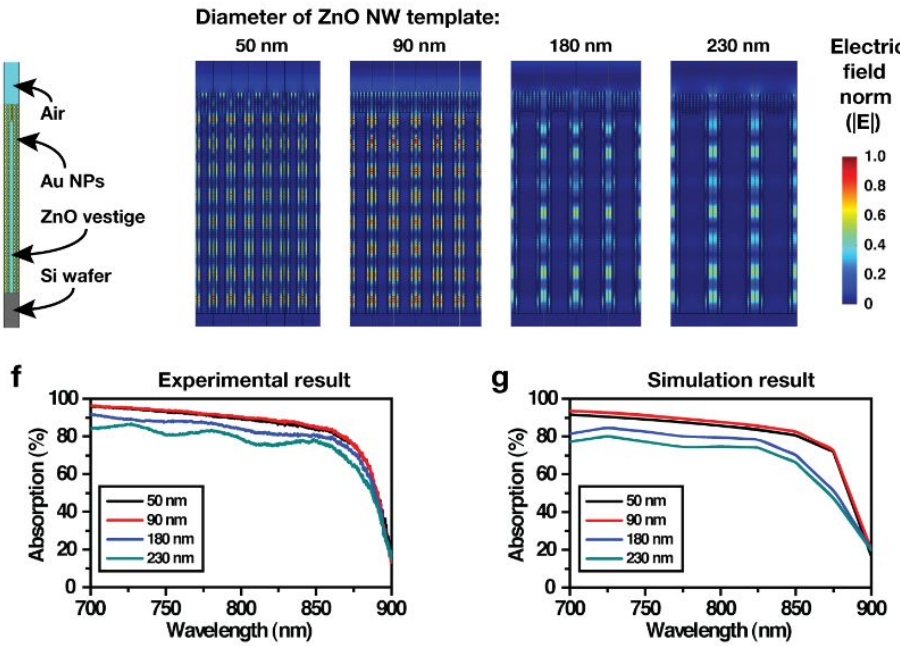

Figure 2. Fabrication and properties of the SERS substrate. (a) ZnO NWs fabricated on Si substrate using hydrothermal synthesis. (b) 3D Au NP deposited in a pillar array format using the liquid phase deposition. SEM images of (c) ZnO NW template and (d) 3D Au NP clusters. (e) Electric field norm (|E|) of 3D stacked Au-NP cluster SERS substrate with various diameters of ZnO NW templates. (f) Experimental and $(\mathrm{g})$ simulation results of absorption of the SERS substrates made with $\mathrm{ZnO}$ NWs of four different diameters. 


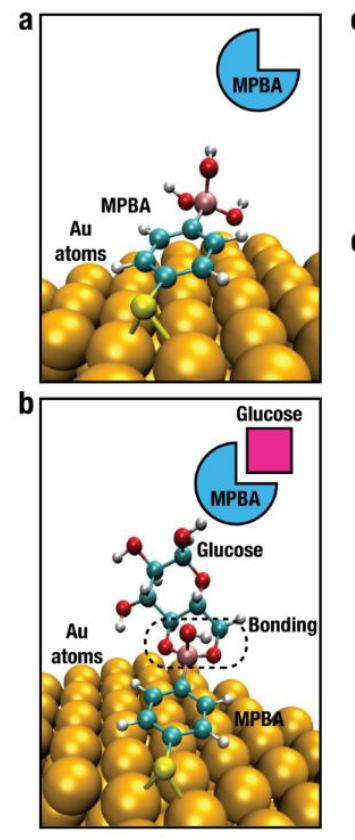

e<smiles>O=CC12C(=O)C(=O)C(C(=O)C1=O)C2=O</smiles>

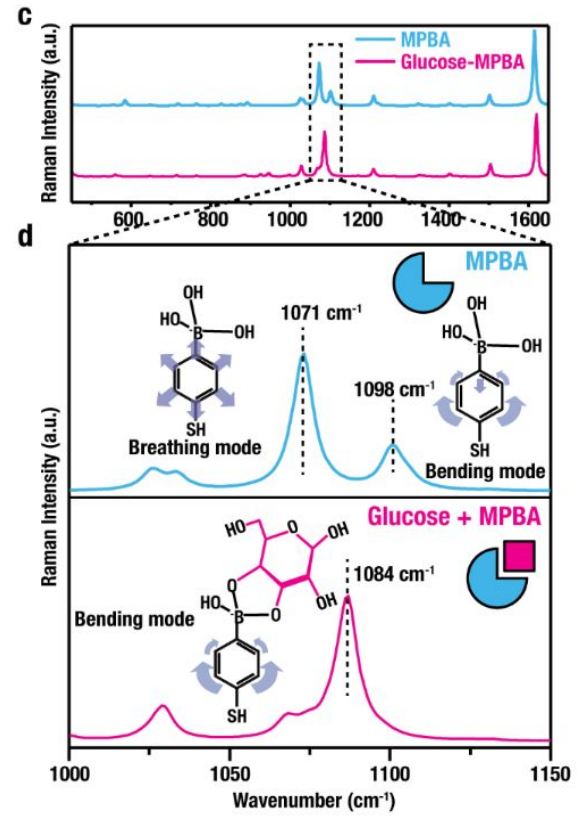

f

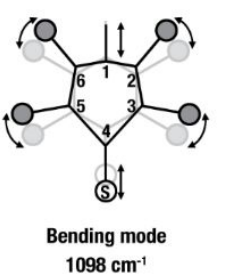

g<smiles>CC1C(O)C(O)C(O)C(O)C1O</smiles>

Constrained bending mode

Figure 3. Analysis of SERS-peak shift using numerical simulations based on the density functional theory (DFT). DFT simulation geometries used for studying ( $\left.\mathrm{OH}^{-}\right)$-MPBA's Raman-peak shifting mechanism (a) before glucose bonding and (b) after glucose bonding. (c) DFTsimulation of $\left(\mathrm{OH}^{-}\right)$-MPBA and $\left(\mathrm{OH}^{-}\right)-\mathrm{MPBA}$-glucose bonded SERS spectra in mildly basic ( $\mathrm{pH}$ 7.4) PBS. (d) SERS spectra of MPBA showing the C-S-stretching-coupled C-ring "breathing" mode at $1071 \mathrm{~cm}^{-1}$, the C-S-stretching-coupled C-ring "bending" mode at $1098 \mathrm{~cm}^{-1}$, and the glucose-bound C-S-stretching-coupled C-ring "constrained bending" mode at $1084 \mathrm{~cm}^{-1}$ along with molecular structures indicating the vibrational motions. Schematic diagrams showing the in-plane $\mathrm{C}$-ring vibrational modes of $\left(\mathrm{OH}^{-}\right)$-MPBA: (e) "breathing" mode at 1071 $\mathrm{cm}^{-1}$, (f) "bending" mode at $1098 \mathrm{~cm}^{-1}$, and (g) "constrained bending" mode of glucose-bound (OH-)-MPBA at $1084 \mathrm{~cm}^{-1}$. 


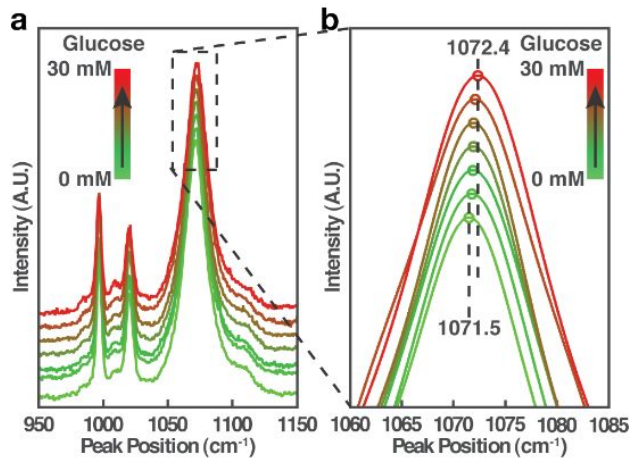

C

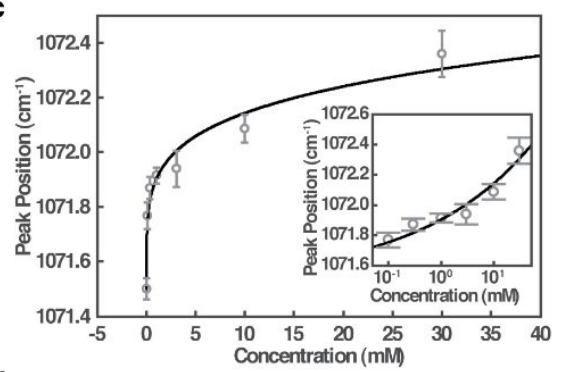

d

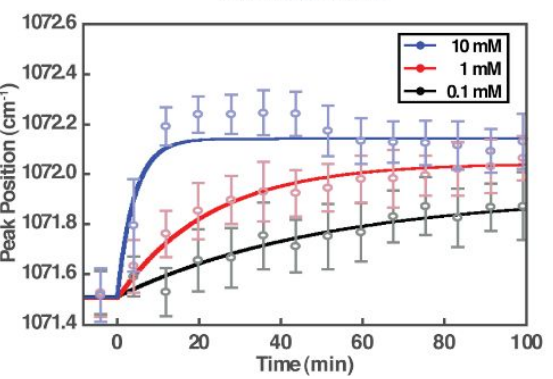

Figure 4. Measuring glucose concentrations by tracking Raman-peak positions. (a) Normalized SERS spectra of MPBA in the presence of glucose concentrations ranging from 0 to $30 \mathrm{mM}$. (b) Magnified view of SERS peaks near $1071 \mathrm{~cm}^{-1}$ for glucose concentrations from 0 to $30 \mathrm{mM}$. (c) SERS peak position vs. glucose concentration for glucose concentrations between 0 and $30 \mathrm{mM}$. (d) Initial dynamic shifting of SERS peak positions vs. time when $0.1,1$, and $10 \mathrm{mM}$ glucose solutions are applied at $\mathrm{t}=0$; initial slopes are a function of glucose concentration and distinct at each concentration.
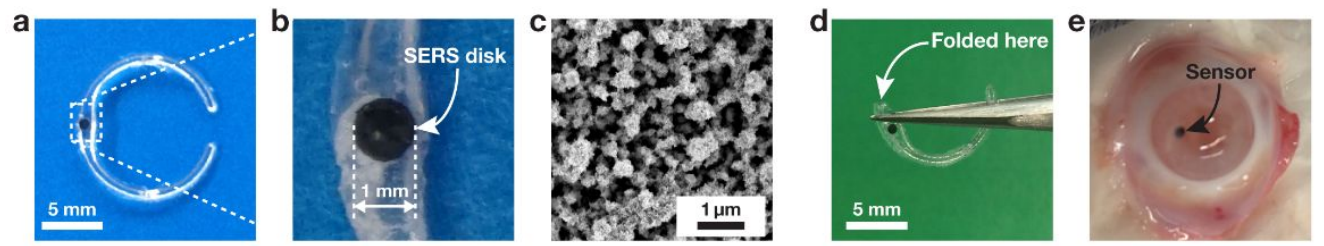

f
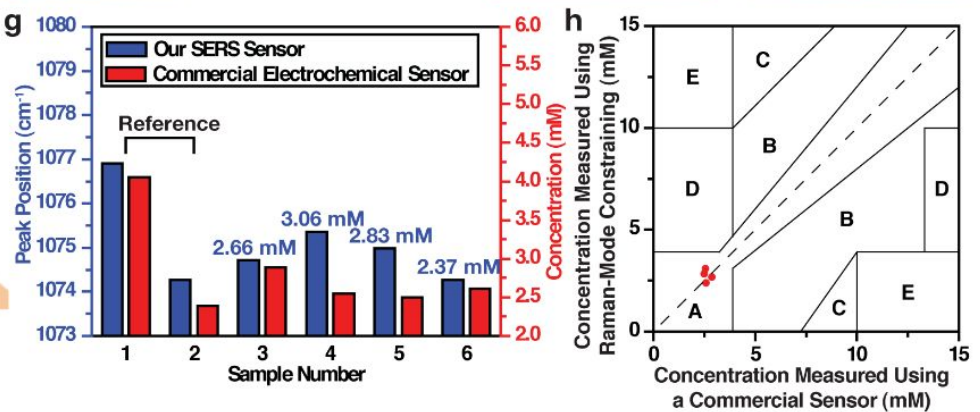

Figure 5. Measuring glucose concentrations in the aqueous humor of ex vivo rabbit eyes. (a) A photo of the SERS-disk-mounted C-shaped implant made of PDMS; the loop diameter is $10 \mathrm{~mm}$, the circular shaped beam is $1 \mathrm{~mm}$ wide, and the mounting region is $1.5 \mathrm{~mm}$ wide. (b) A photographic image of a SERS disk. (c) A SEM image of 3D-stacked Au NP clusters fabricated on the SERS disk. (d) A photo of the folded SERS-disk-mounted implant. (e) A photo of the implant inserted inside the anterior chamber of the ex vivo rabbit eye. (f) Schematic illustration of the glucose measurement made using the SERS implant inside the anterior chamber of an ex vivo rabbit eye. (g) Glucose concentration measurements made using our Raman-mode constraining approach (blue) in comparison with readouts concurrently obtained 
using a commercial electrochemical glucose sensor (red). The first two measurements (\#1 and \#2, blue) made using Raman-mode constraining served as references to calculate the other four measurements (\#3-\#6), and the corresponding glucose concentrations are displayed in blue over the histograms; (h) A Clarke error grid analysis of the glucose measurements using our Raman-mode constraining approach in ex vivo rabbit eyes.

\section{ASSOCIATED CONTENT}

\section{Supporting Information}

The Supporting Information is available free of charge on the ACS Publications website.

Experimental Procedures, characteristics of the SERS substrate, enhancement factor calculation, SERS spectra of MPBA and glucose-bonded MPBA, bench-top test of glucose concentration, signal processing for static Raman data, analytical glucose-sensing model, stability of test over a 1-month period, ex vivo measurements of glucose in the anterior chamber of the rabbit eyes, and glucose sensing technologies. (PDF)

Molecular vibration of the $\mathrm{C}-\mathrm{S}$ stretching-coupled C-ring "breathing" mode of $\left(\mathrm{OH}^{-}\right)-\mathrm{MPBA}, \mathrm{C}$-S-stretching-coupled C-ring "bending" mode of $\left(\mathrm{OH}^{-}\right)$-MPBA, and C-S-stretching-coupled $\mathrm{C}$ ring "constrained-bending" mode of $\left(\mathrm{OH}^{-}\right)-\mathrm{MPBA}$ bound with glucose. (AVI)

\section{AUTHOR INFORMATION}

\section{Corresponding Author}

*azayak@bgsu.edu

*hchoo@caltech.edu

\section{Author Contributions}

D.Y., J.O.L., and H. Choo conceived the study. D.Y. performed most of sample fabrication, experiments, and data processing under the supervision of H. Choo. S.A. conducted DFT simulations to identify the mode-shifting mechanism under the supervision of A.T.Z.. J.O.L., H. Cho, and S.K. contributed at various stages during sample fabrication and measurements. R.H.S. contributed on the optical simulation and spectroscopy of the SERS substrates. S.K. V. N. and Y.-Z.Y. contributed to dataprocessing algorithm development. D.Y. and H. Choo wrote the manuscript with S.A. and A.T.Z. and with a significant contribution from S.K.. J.O.L., H.Cho., and Y.-Z.Y. also assisted with manuscript preparation. All authors discussed the results and commented on the manuscript.

\section{Notes}

The authors declare no competing financial interest.

\section{ACKNOWLEDGMENT}

The authors thank Dr. Robert Grubbs (Department of Chemistry, California Institute of Technology) and Dr. Massimo Olivucci (Department of Chemistry, Bowling Green State University) for helpful discussions on boronic acid and the computational modeling with solvents, respectively. The research was funded by Samsung Grand Research Opportunity and Heritage Medical Research Institute Inaugural Principle Investigator Program. Computational resources were provided by the Texas Advanced Computer Center (XSEDE Program) and Ohio Supercomputer Center (OSC).

\section{REFERENCES}

(1) Narayan, K. M. V.; Gregg, E. W.; Engelgau, M. M.; Moore, B.; Thompson, T. J.; Williamson, D. F.; Vinicor, F. Diabetes Care 2000, 23, 1794-1798.
(2) Kovatchev, B. P. Nat. Rev. Endocrinol. 2017, 13, 425-436.

(3) Waldron-Lynch, F.; Herold, K. C. Nat. Clin. Pract. Endocrinol. Metab. 2009, 5, 82-83.

(4) Lin, Y.; Lu, F.; Tu, Y.; Ren, Z. Nano Lett. 2004, 4, 191-195.

(5) Besteman, K.; Lee, J.-O.; Wiertz, F. G. M.; Heering, H. A.; Dekker, C. Nano Lett. 2003, 3, 727-730.

(6) Veiseh, O.; Tang, B. C.; Whitehead, K. A.; Anderson, D. G.; Langer, R. Nat. Rev. Drug Discov. 2015, 14, 45-57.

(7) Yu, H. Y.; Xu, M. Q.; Yu, S. H.; Zhao, G. C. Int. J. Electrochem. Sci. 2013, 8, 8050-8057.

(8) Reitz, E.; Jia, W. Z.; Gentile, M.; Wang, Y.; Lei, Y. Electroanalysis 2008, 20, 2482-2486.

(9) Heinemann, L. J. Diabetes Sci. Technol. 2008, 2, 919-921.

(10) Emaminejad, S.; Gao, W.; Wu, E.; Davies, Z. A.; Nyein, H. Y. Y.; Challa, S.; Ryan, S. P.; Fahad, H. M.; Chen, K.; Shahpar, Z.; Talebi, S.; Milla, C.; Javey, A.; Davis, R. W. Proc. Natl. Acad. Sci. U.S.A. 2017, 114, 4625-4630.

(11) Gao, W.; Emaminejad, S.; Nyein, H. Y. Y.; Challa, S.; Chen, K. V.; Peck, A.; Fahad, H. M.; Ota, H.; Shiraki, H.; Kiriya, D.; Lien, D. H.; Brooks, G. A.; Davis, R. W.; Javey, A. Nature 2016, 529, 509514.

(12) Lee, H.; Choi, T. K.; Lee, Y. B.; Cho, H. R.; Ghaffari, R.; Wang, L.; Choi, H. J.; Chung, T. D.; Lu, N. S.; Hyeon, T.; Choi, S. H.; Kim, D. H. Nat. Nanotechnol. 2016, 11, 566-572.

(13) Lee, H.; Song, C.; Hong, Y. S.; Kim, M. S.; Cho, H. R.; Kang, T.; Shin, K.; Choi, S. H.; Hyeon, T.; Kim, D. H. Sci. Adv. 2017, 3 , e1601314.

(14) Tierney, M. J.; Kim, H. L.; Burns, M. D.; Tamada, J. A.; Potts, R. O. Electroanalysis 2000, 12, 666-671.

(15) Sakaguchi, K.; Hirota, Y.; Hashimoto, N.; Ogawa, W.; Hamaguchi, T.; Matsuo, T.; Miyagawa, J.-I.; Namba, M.; Sato, T.; Okada, S.; Tomita, K.; Matsuhisa, M.; Kaneto, H.; Kosugi, K.; Maegawa, H.; Nakajima, H.; Kashiwagi, A. J. Diabetes Sci. Technol. 2013, 7, 678-688.

(16) Toghill, K. E.; Compton, R. G. Int. J. Electrochem. Sci. 2010, 5, 1246-1301.

(17) Beers, M. H.; Fletcher, A. J. The Merck Manual of Medical Information, 2nd ed.; Merck Research Laboratories: Whitehouse Station, New Jersey, 2003.

(18) Vaddiraju, S.; Burgess, D. J.; Tomazos, I.; Jain, F. C.; Papadimitrakopoulos, F. J. Diabetes Sci. Technol. 2010, 4, 1540-1562.

(19) Weiss, R.; Yegorchikov, Y.; Shusterman, A.; Raz, I. Diabetes Technol. Ther. 2007, 9, 68-74.

(20) Sapozhnikova, V. V.; Kuranov, R. V.; Cicenaite, I.; Esenaliev, R. O.; Prough, D. S. J. Biomed. Opt. 2008, 13, 021112.

(21) Cameron, B. D.; Anumula, H. Diabetes Technol. Ther. 2006, 8 , 156-164.

(22) Rounds, R. M.; Ibey, B. L.; Beier, H. T.; Pishko, M. V.; Cote, G. L. J. Fluoresc. 2007, 17, 57-63.

(23) Oliver, N. S.; Toumazou, C.; Cass, A. E. G.; Johnston, D. G. Diabetic Med. 2009, 26, 197-210.

(24) Liu, N.; Mesch, M.; Weiss, T.; Hentschel, M.; Giessen, H. Nano Lett. 2010, 10, 2342-2348.

(25) Amerov, A. K.; Chen, J.; Small, G. W.; Arnold, M. A. Anal. Chem. 2005, 77, 4587-4594.

(26) Feng, J.; Siu, V. S.; Roelke, A.; Mehta, V.; Rhieu, S. Y.; Palmore, G. T. R.; Pacifici, D. Nano Lett. 2012, 12, 602-609.

(27) McCreery, R. L., Raman Spectroscopy for Chemical Analysis; John Wiley \& Sons: New York, 2000.

(28) Campion, A.; Kambhampati, P. Chem. Soc. Rev. 1998, 27, 241250.

(29) Willets, K. A.; Van Duyne, R. P. Annu. Rev. Phys. Chem. 2007, 58, 267-297.

(30) Wang, D.; Zhu, W.; Best, M. D.; Camden, J. P.; Crozier, K. B. Nano Lett. 2013, 13, 2194-2198.

(31) Li, Z.-Y.; Xia, Y. Nano Lett. 2010, 10, 243-249. 
(32) Ahmed, A.; Gordon, R. Nano Lett. 2012, 12, 2625-2630.

(33) Cho, H.; Baker, B. R.; Wachsmann-Hogiu, S.; Pagba, C. B.; Laurence, T. A.; Lane, S. M.; Lee, L. P.; Tok. J. B.-H. Nano Lett. 2008, 8, 4386-4390.

(34) Kang, T.; Yoo, S. M.; Yoon, I.; Lee, S. Y.; Kim, B. Nano Lett. 2010, 10, 1189-1193.

(35) Lyandres, O.; Shah, N. C.; Yonzon, C. R.; Walsh, J. T.; Glucksberg, M. R.; Van Duyne, R. P. Anal. Chem. 2005, 77, 61346139.

(36) Ma, K.; Yuen, J. M.; Shah, N. C.; Walsh, J. T.; Glucksberg, M. R.; Van Duyne, R. P. Anal. Chem. 2011, 83, 9146-9152.

(37) Sharma, B.; Bugga, P.; Madison, L. R.; Henry, A. I.; Blaber, M. G.; Greeneltch, N. G.; Chiang, N. H.; Mrksich, M.; Schatz, G. C.; Van Duyne, R. P. J. Am. Chem. Soc. 2016, 138, 13952-13959.

(38) Tong, L. M.; Xu, H. X.; Kall, M. MRS Bull. 2014, 39, 163-168.

(39) Marotta, N. E.; Beavers, K. R.; Bottomley, L. A. Anal. Chem. 2013, $85,1440-1446$.

(40) Sun, X. C.; Stagon, S.; Huang, H. C.; Chen, J.; Lei, Y. RSC Adv. 2014, 4, 23382-23388.

(41) Li, S. S.; Zhou, Q.; Chu, W. Y.; Zhao, W.; Zheng, J. W. Phys. Chem. Chem. Phys. 2015, 17, 17638-17645.

(42) Kitagawa, T.; Tashiro, K.; Yabuki, K. J. Polym. Sci. Pt. BPolym. Phys. 2002, 40, 1269-1280.

(43) Roelli, P.; Galland, C.; Piro, N.; Kippenberg, T. J. Nat. Nanotechnol. 2016, 11, 164-169.

(44) Guerrini, L.; Pazos, E.; Penas, C.; Vazquez, M. E.; Mascarenas, J. L.; Alvarez-Puebla, R. A. J. Am. Chem. Soc. 2013, 135, 10314 10317.

(45) Zhuang, H. J.; Zhu, W. F.; Yao, Z. Y.; Li, M.; Zhao, Y. L. Talanta 2016, 153, 186-190.

(46) Chen, L.; Zhao, Y.; Wang, Y. X.; Zhang, Y. J.; Liu, Y.; Han, X. X.; Zhao, B.; Yang, J. H. Analyst, 2016, 141, 4782-4788.

(47) Dong, J.; Liu, T.; Meng, X. M.; Zhu, J. Y.; Shang, K.; Ai, S. Y.;

Cui, S. L. J. Solid State Electrochem. 2012, 16, 3783-3790.

(48) Sakalak, H.; Ulasan, M.; Yavuz, E.; Camli, S. T.; Yavuz, M. S. J. Nanopart. Res. 2014, 16, 2767.

(49) James, T. D.; Phillips, M. D.; Shinkai, S. Boronic Acids in Saccharide Recognition, 1st ed.; Royal Society of Chemistry: Cambridge, UK, 2006.

(50) Lorand, J. P.; Edwards, J. O. J. Org. Chem. 1959, 24, 769-774. 1609 .

(51) Springsteen, G.; Wang, B. H. Chem. Commun. 2001, 0, 1608 -

(52) Yang, D.; Cho, H.; Koo, S.; Vaidyanathan, S. R.; Woo, K.; Yoon, Y.; Choo, H. ACS Appl. Mater. Interfaces 2017, 9, 19092-19101.

(53) Cho, H.; Kumar, S.; Yang, D.; Vaidyanathan, S.; Woo, K.; Garcia, I.; Shue, H. J.; Yoon Y.; Ferreri, K.; Choo, H. ACS Sens 2018, $3,65-71$.
(54) Orendorff, C. J.; Gole, A.; Sau, T. K.; Murphy, C. J. Anal Chem. 2005, 77, 3261-3266.

(55) Sun, D.; Qi, G. H.; Xu, S. P.; Xu, W. Q. $R S C A d v$. 2016, 6, 53800-53803.

(56) Sen, D. K.; Sarin, G. S. Br. J. Ophthalmol. 1980, 64, 693-695.

(57) Davies, P. D.; Duncan, G.; Pynsent, P. B.; Arber, D. L.; Lucas, V. A. Exp. Eye Res. 1984, 39, 605-609.

(58) Schrader, W. F.; Stehberger, B.; Meuer, P. Invest. Ophthalmol Vis. Sci. 2002, 43, 3263.

(59) Springsteen, G.; Wang, B. H. Tetrahedron 2002, 58, 52915300 .

(60) Kong, K. V.; Ho, C. J. H.; Gong, T. X.; Lau, W. K. O.; Olivo, M. Biosens. Bioelectron. 2014, 56, 186-191.

(61) Sun, F.; Bai, T.; Zhang, L.; Ella-Menye, J.-R.; Liu, S.; Nowinski, A. K.; Jiang, S.; Yu, Q. Anal. Chem. 2014, 86, 2387-2394.

(62) Kawasaki, T.; Akanuma, H.; Yamanouchi, T. Y. Diabetes Care 2002, 25, 353-357.

(63) Harding, J. J.; Hassett, P.; Rixon, K. C.; Bron, A. J.; Harvey, D. J. Curr. Eye Res. 1999, 19, 131-136.

(64) Bélanger, M. C.; Marois, Y. J. Biomed Mater Res. 2001, 58, 467-477.

(65) Peterson, S. L.; McDonald, A.; Gourley, P. L.; Sasaki, D. Y. J. Biomed Mater Res. 2005, 72, 10-18.

(66) Kim, S. H.; Moon, J. H.; Kim, J. H.; Jeong, S. M.; Lee, S. H. Biomed. Eng. Lett. 2011, 1, 199-203.

(67) Lo, R.; Li, P. Y.; Saati, S.; Agrawal, R.; Humayun, M. S.; Meng, E. Lab Chip, 2008, 8, 1027-1030.

(68) Humayun, M.; Santos, A.; Altamirano, J.C.; Ribeiro, R.; Gonzalez, R.; de la Rosa, A.; Shih, J.; Pang, C.; Jiang, F.; Calvillo, P.; Huculak, J.; Zimmerman, J.; Caffey, S. Transl. Vis. Sci. Technol. 2014, 3,5 .

(69) Goel, M.; Picciani, R. G.; Lee, R. K.; Bhattacharya, S. K. Open Ophthalmol J. 2010, 4, 52-59.

(70) Baca, J. T.; Finegold, D. N.; Asher, S. A.; Ocul. Surf. 2007, 5, 280-293.

(71) Lee, J. O.; Narasimhan, V.; Du, J.; Ndjamen, B.; Sretavan, D.; Choo, H. Adv. Healthcare Mater. 2017, 6, 1601356.

(72) Algvere, P. V.; Torstensson, P. A. L.; Tengroth, B. M. Invest. Ophthalmol. Vis. Sci. 1993, 34, 349-354.

(73) World Health Organization. Definition and Diagnosis of Diabetes Mellitus and Intermediate Hyperglycaemia, ISBN: 92-4159493-4; WHO Document Production Services: Geneva, Switzerland, 2006. Online version at http://www.who.int/diabetes/publications/diagnosis_diabetes2006/en/ (accessed September 9, 2018)

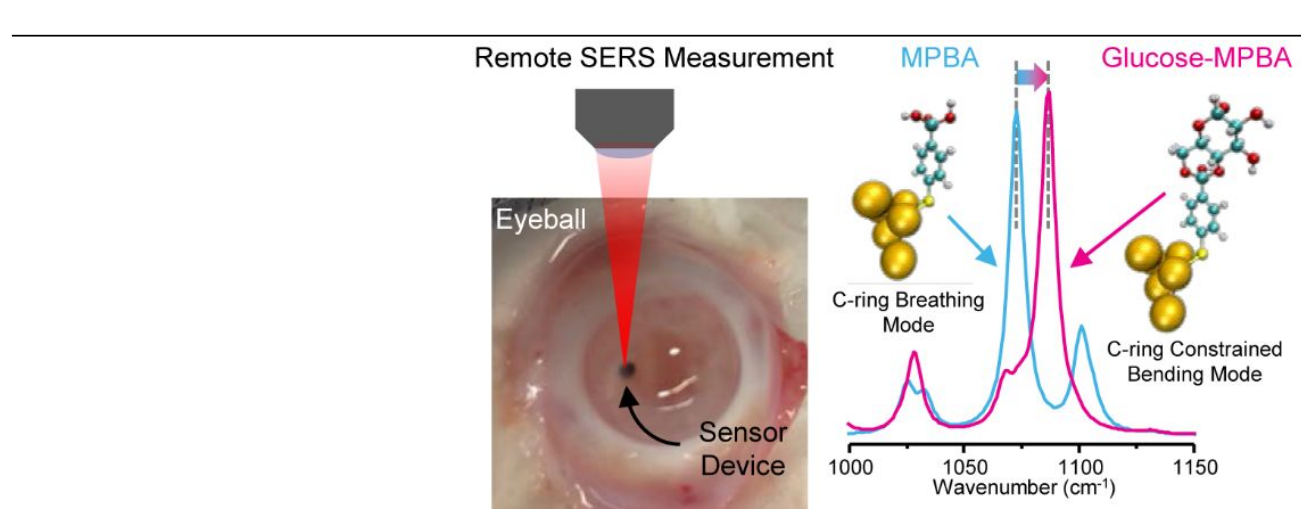


a

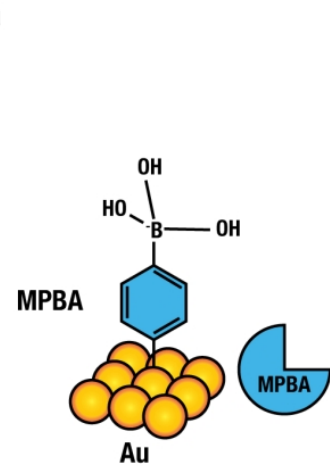

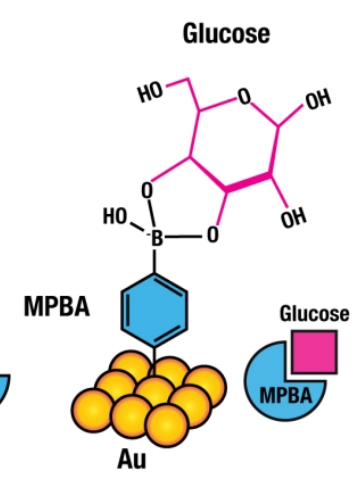

b

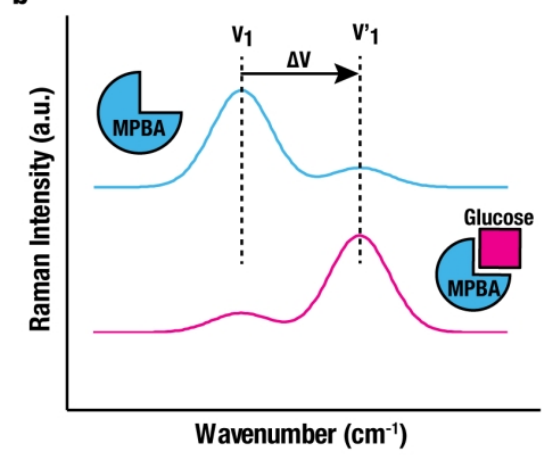

C

Au NP synthesized on ZnO NWs

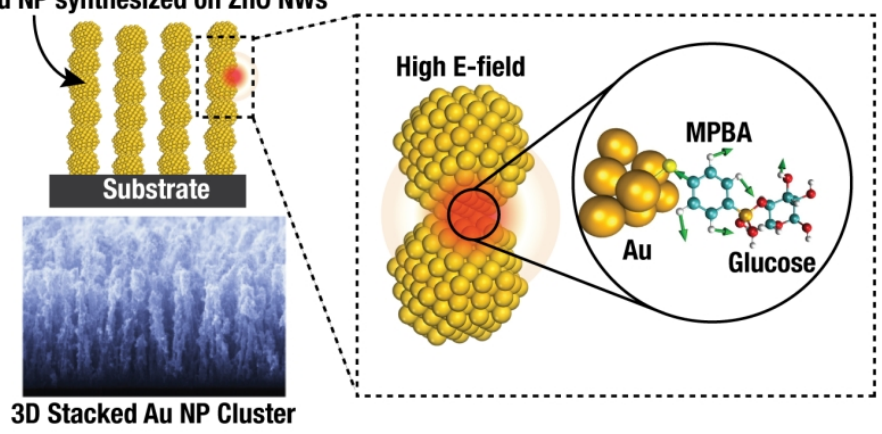

Figure 1. Glucose-detection mechanism based on SERS-peak shifting. (a) Schematic illustrations of MPBA (left) and glucose-bound MPBA (right). (b) A shift in the dominant Raman peak of MPBA from $v_{1}$ to $v_{1}{ }^{\prime}$ resulting from glucose bonding with MPBA. (c) Schematic illustration and SEM of highly uniform surfaceenhanced Raman scattering using 3D Au-NP clusters stacked in a vertical pillar arrangement. 

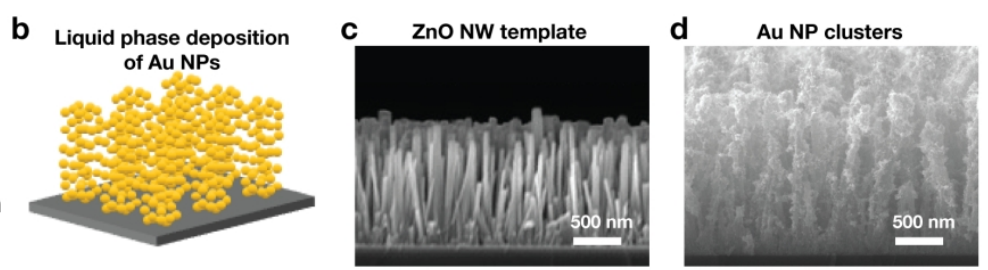

e

Diameter of ZnO NW template:
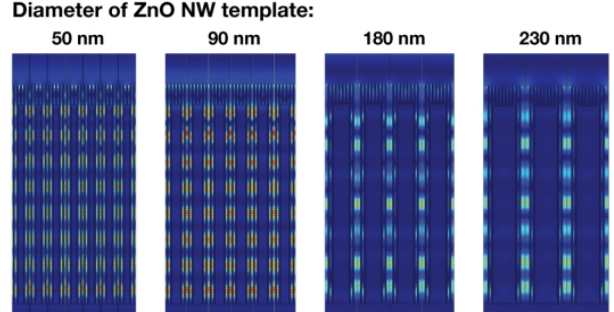

\section{Electric}

field

norm

(|E|)

1.0
0.8

0.8
0.6
0.4
0.2
0
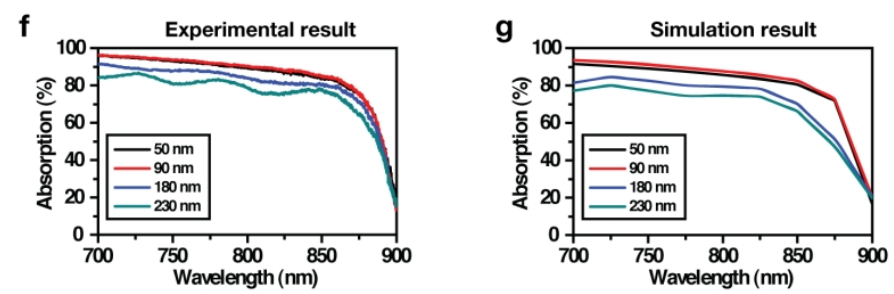

Figure 2. Fabrication and properties of the SERS substrate. (a) ZnO NWs fabricated on Si substrate using hydrothermal synthesis. (b) 3D Au NP deposited in a pillar array format using the liquid phase deposition. SEM images of (c) ZnO NW template and (d) 3D Au NP clusters. (e) Electric field norm (|E|) of 3D stacked Au-NP cluster SERS substrate with various diameters of ZnO NW templates. (f) Experimental and ( $g$ ) simulation results of absorption of the SERS substrates made with ZnO NWs of four different diameters.

$178 \times 127 \mathrm{~mm}(300 \times 300 \mathrm{DPI})$ 

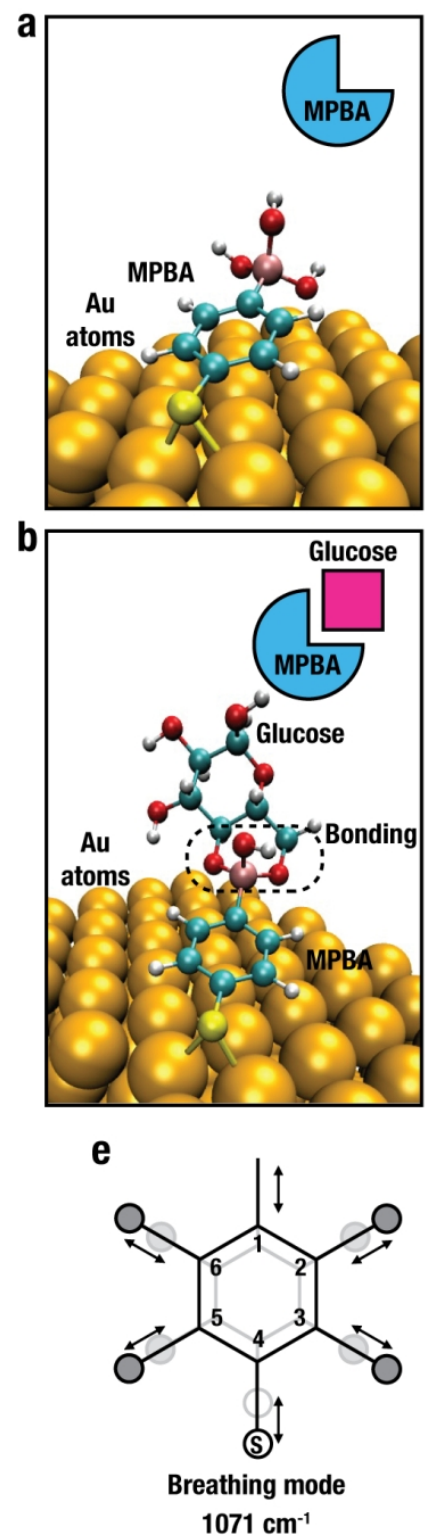

\section{C}

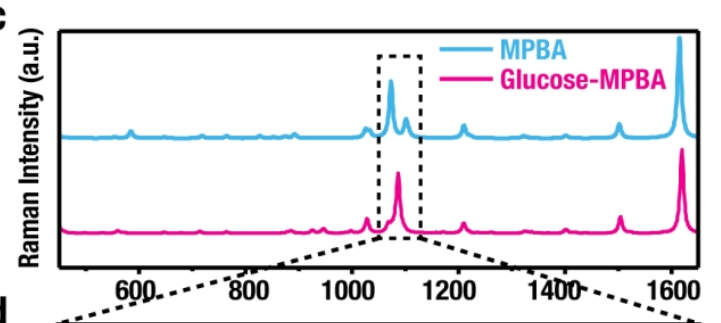

d

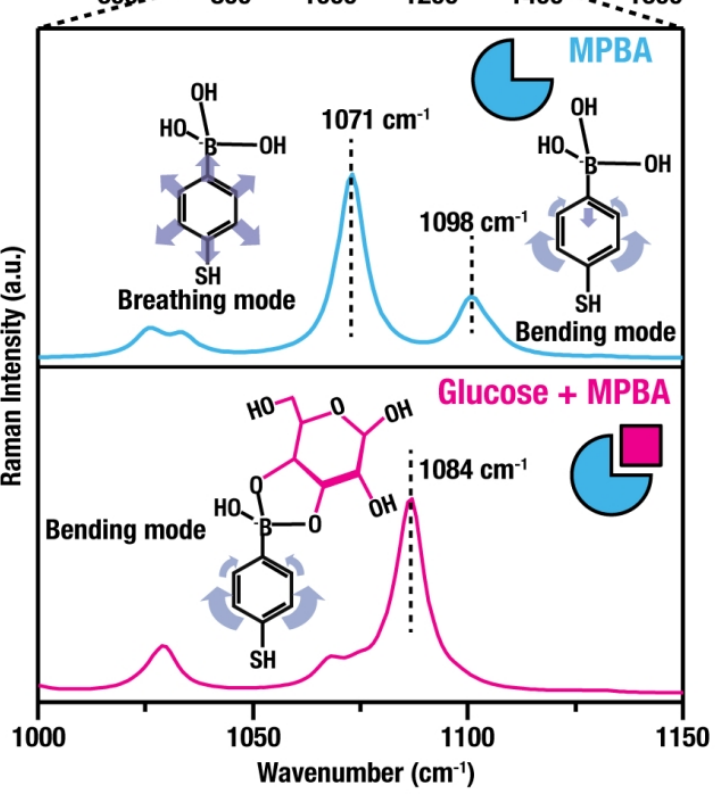

f

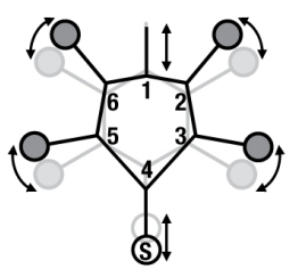

Bending mode $1098 \mathrm{~cm}^{-1}$ g<smiles>CC12CC1C(=O)C(O)C(=O)C(=O)C2=O</smiles>

Constrained bending mode $1084 \mathrm{~cm}^{-1}$

Figure 3. Analysis of SERS-peak shift using numerical simulations based on the density functional theory (DFT). DFT simulation geometries used for studying $\left(\mathrm{OH}^{-}\right)-\mathrm{MPBA}^{\prime} \mathrm{s}$ Raman-peak shifting mechanism (a) before glucose bonding and (b) after glucose bonding. (c) DFT-simulation of $\left(\mathrm{OH}^{-}\right)-\mathrm{MPBA}$ and $\left(\mathrm{OH}^{-}\right)-\mathrm{MPBA}^{-}$ glucose bonded SERS spectra in mildly basic ( $\mathrm{pH}$ 7.4) PBS. (d) SERS spectra of MPBA showing the C-Sstretching-coupled C-ring "breathing" mode at $1071 \mathrm{~cm}^{-1}$, the C-S-stretching-coupled C-ring "bending" mode at $1098 \mathrm{~cm}^{-1}$, and the glucose-bound C-S-stretching-coupled C-ring "constrained bending" mode at $1084 \mathrm{~cm}^{-1}$ along with molecular structures indicating the vibrational motions. Schematic diagrams showing the in-plane C-ring vibrational modes of $\left(\mathrm{OH}^{-}\right)$-MPBA: (e) "breathing" mode at $1071 \mathrm{~cm}^{-1}$, ( $\mathrm{f}$ ) "bending" mode at $1098 \mathrm{~cm}^{-1}$, and $(\mathrm{g})$ "constrained bending" mode of glucose-bound $\left(\mathrm{OH}^{-}\right)-\mathrm{MPBA}$ at $1084 \mathrm{~cm}^{-1}$. 


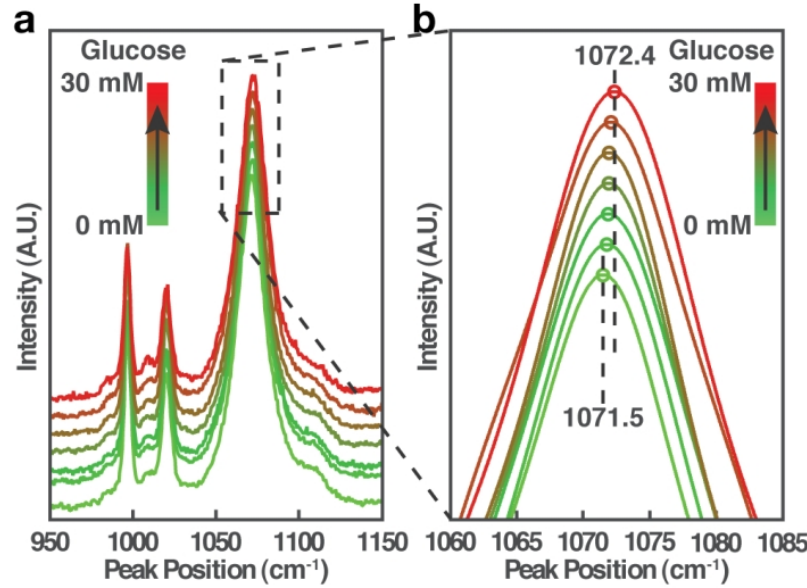

C
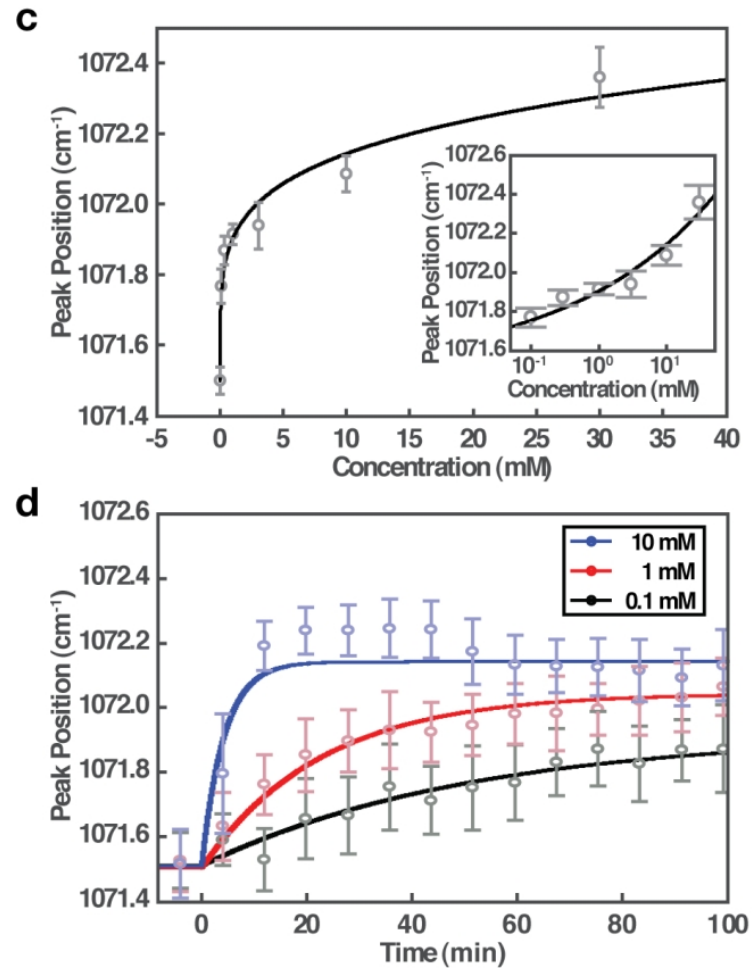

Figure 4. Measuring glucose concentrations by tracking Raman-peak positions. (a) Normalized SERS spectra of MPBA in the presence of glucose concentrations ranging from 0 to $30 \mathrm{mM}$. (b) Magnified view of SERS peaks near $1071 \mathrm{~cm}^{-1}$ for glucose concentrations from 0 to $30 \mathrm{mM}$. (c) SERS peak position vs. glucose concentration for glucose concentrations between 0 and $30 \mathrm{mM}$. (d) Initial dynamic shifting of SERS peak positions vs. time when $0.1,1$, and $10 \mathrm{mM}$ glucose solutions are applied at $\mathrm{t}=0$; initial slopes are a function of glucose concentration and distinct at each concentration.

$83 \times 164 \mathrm{~mm}(300 \times 300$ DPI $)$ 

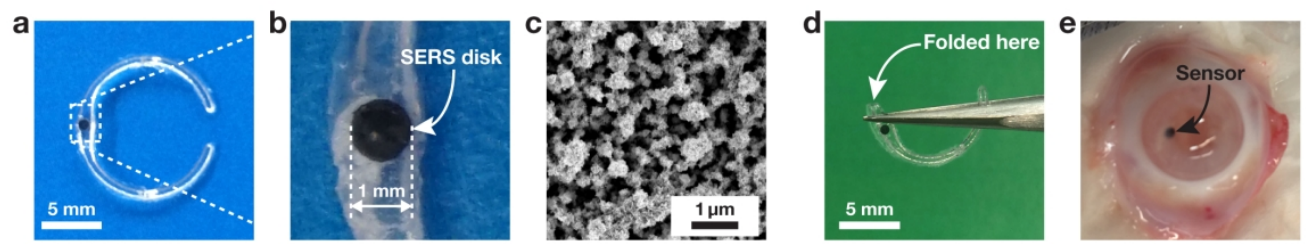

f
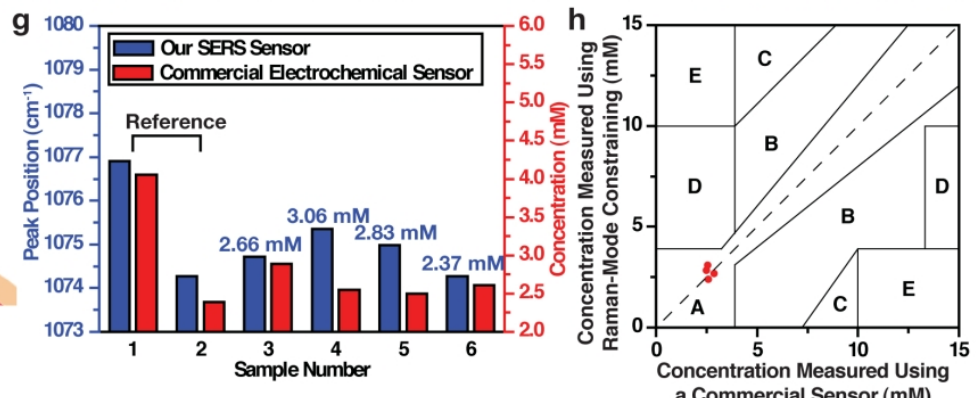

Figure 5. Measuring glucose concentrations in the aqueous humor of ex vivo rabbit eyes. (a) A photo of the SERS-disk-mounted C-shaped implant made of PDMS; the loop diameter is $10 \mathrm{~mm}$, the circular shaped beam is $1 \mathrm{~mm}$ wide, and the mounting region is $1.5 \mathrm{~mm}$ wide. (b) A photographic image of a SERS disk. (c) A SEM image of 3D-stacked Au NP clusters fabricated on the SERS disk. (d) A photo of the folded SERSdisk-mounted implant. (e) A photo of the implant inserted inside the anterior chamber of the ex vivo rabbit eye. (f) Schematic illustration of the glucose measurement made using the SERS implant inside the anterior chamber of an ex vivo rabbit eye. (g) Glucose concentration measurements made using our Raman-mode constraining approach (blue) in comparison with readouts concurrently obtained using a commercial electrochemical glucose sensor (red). The first two measurements (\#1 and \#2, blue) made using Ramanmode constraining served as references to calculate the other four measurements (\#3-\#6), and the corresponding glucose concentrations are displayed in blue over the histograms; (h) A Clarke error grid analysis of the glucose measurements using our Raman-mode constraining approach in ex vivo rabbit eyes.

$178 \times 90 \mathrm{~mm}(300 \times 300$ DPI $)$ 